THE ANALYST.

\title{
NOTES ON PRUSSIAN BLUE.
}

\author{
By Frank H. Leeds, F.I.C. \\ (Read at the Meeting, December 2, 1896.)
}

A study of the figures given by Messrs. Parry and Coste (Analyst, xxi , 225) as representing the composition of commercial Prussian blue, and more especially the manner in which the authors use the term "pure " blue in its chemical as opposed to its trade significance, have made it seem worth placing on record the experience gained of this substance in the laboratory of a printing-ink works, where the pigments employed have to undergo a more rigorous examination than is perhaps necessary in the case of oil paints.

In the manufacture of printers' ink the material known to chemists as " Prussian" blue is used for two distinct purposes: (1) in the production of a blue ink to be sold as such, and (2) in the preparation of the better qualities of black ink as a means of correcting the invariable brown shade of lamp-black. In this trade Prussian blue is met with under four different names : bronze, pure, Chinese, and "Prussian " blue ; but although all of these are equally pure from the laboratory point of view, each variety possesses, when ground in "varnish," a distinct shade of colour, consequently they rank, from the printers' standpoint, as four individual pigments, Bronze blue is the basis of that dark-blue ink so often seen on small advertisements and the covers of magazines, which is specially valued for the coppery lustre, or bronze, it possesses when viewed at the proper angle, more particularly when the impression has been made by lithography. Pure blue yields almost the same shade of ink, but devoid of bronze, and it is therefore seldom used except in making black inks. Both kinds have much the same appaarance when in the lump or powder, and it is exceedingly difficult to judge the amount of bronze any ink will have from a mere inspection of the dry pigment. In fact, the material having the most pronounced coppery lustre is usually known as Chinese blue; but this, when ground in oil, produces a brighter and slightly paler cast of blue, almost devoid of bronze. "Prussian" blue is not so often met with; it yields a much darker, duller shade of ink, more resembling indigo as a water-colour pigment, and some samples contain a considerable excess of basic ("extra-radicle") iron. Both pure and bronze blues may be obtained in several slightly different shades, varying from the green to the violet side of blue itself.

A regular examination, extending over several year, of the bronze and pure blues supplied by the leading manufacturers has shown that this pigment varies in composition even less than the samples quoted by Messrs. Parry and Coste; but at the same time it has amply proved that the substance may be accurately valued-apart from the question of shade proper-according to the proportion of acid ("intraradicle") iron it contains. With the exception that no nitrogen estimations were made, the samples were analysed in the manner given in the paper referred to, but as alumina was almost invariably found to be present in the basic iron precipitate, and titrations showed that it was practically constant in amount, it was usually returned simply as $\mathrm{Fe}_{2} \mathrm{O}_{3}$, both acid and basic iron solutions being always oxidized with nitric acid before the final precipitation with ammonia. Occasionally a sample containing 
up to 20 per cent. of an inert white base is offered under the name of "pure blue"; but this must be regarded either as a mis-description or an adulteration, for such a material is well known under its correct designation of "Antwerp" blue. The average figures obtained on the analysis of the best qualities of these pigments, after drying at $100^{\circ} \mathrm{C}$., are given below, and from these it would appear that the previous authors' generalizations are perfectly correct, but that their requirement of 30 per cent. of total iron should be increased to 34 per cent., or preferably that at least 16 per cent. of acid iron should be insisted on.

$\begin{array}{cccc}\text { Pigment. } & & \begin{array}{c}\text { Basic iron } \\ \text { per cent. }\end{array} & \begin{array}{c}\text { Acid iron } \\ \text { per cent. }\end{array} \\ \text { Genuine blues : } & \text { maximum } & 19 \cdot 14 & 17 \cdot 16 \\ \text { (bronze, pure, } & \text { minimum } & 18.37 & 15 \cdot 35 \\ \text { or Chinese), ( } & \text { mean } & 18.90 & 16 \cdot 48 \\ \text { "Prussian "blue } & \text { " } & 22 \cdot 83 & 10 \cdot 01 \\ \text { Adulterated "pure" , } & & 13 \cdot 41 & 12.84 \\ \text { or Antwerp blue } & \text { " } & & \end{array}$

Discussion.

Mr. J.. H. Coste expressed satisfaction at the extent to which, so far as could be gathered from the portion of the paper read, the results obtained by Mr. Parry and himself had been corroborated by Mr. Leeds, whose experience on the subject was much greater than their own.

In their paper they had made some remarks on the appearance of the samples they had analysed, some of which had, in the lump, a bright, coppery appearance, while others, though having a glossy conchoidal fracture, were rather bituminous in appearance. When ground up, however, the samples possessing the bright lustre were by no means the darkest blues, and he thought that was what Mr. Leeds stated. The bright coppery blues, as No. III. in our tables, possessed when ground a much finer colour than the darker, more bituminous colours, as, indeed, did the granular, non-lustrous blues. It was a noteworthy fact that the darker samples contained alkaline ferrocyanide.

They considered that the nitrogen determination was a very simple, and at the same time sufficiently accurate, method of estimating, for ordinary painters' purposes, the value of samples of Prussian blue. It could be made very quickly, possessing in this respect a distinct advantage over the determination of the total iron. In the case of pigments ground in oil the percentage of nitrogen had been found to afford a ready means of arriving at a very good idea of the actual quantity of Prussian blue that might be present. 